\title{
KNOWLEDGE IN ACCESS TO THE DEFINITIVE AND VASCULAR PERIPHERAL AERIAL OF PREHOSPITAL CARE STUDENTS
}

\author{
Edgar Lugo Calderon ${ }^{1}$, Sandra Caceres Matta ${ }^{2 *}$, Alexandra Coquel Bru ${ }^{3}$, Carolin Ramos De La Espriella ${ }^{4}$, \\ Ariel Puello Martinez ${ }^{5}$ y Alexander Ruiz Restrepo ${ }^{6}$ \\ ${ }_{1,2,3,4,5,6}$ Corporaciòn Universitaria Rafael Nuñez - CURN. Cartagena de indias, Colombia \\ *Autor de correspondencia: sandra.caceres@ curnvirtual.edu.co
}

Recibido Abril 2018; Aceptado Octubre 2018

\begin{abstract}
We evaluated the knowledge of access to the definitive airway and peripheral vascular of the Technologists in Prehospital Care in training, through a knowledge questionnaire. The sample was applied to the 84 students enrolled and active in the Prehospital Care Technology program of the Corporación Universitaria Rafael Nuñez in the second period of 2018 from the second to the sixth semester. When evaluating the students it was found that they have little empowerment of the basic knowledge to perform invasive procedures in the peripheral vascular pathway, highlighting the lack of protocols, management and function of crystalloid solutions, venoclisis equipment and catheters according to their enumeration which are used. There was also a lack of knowledge in protocols for airway management, adequate management of endotracheal intubation equipment, indications and contraindications for definitive endotracheal intubation and the benefits it generates in patients.
\end{abstract}

Keywords: Peripheral vascular pathway; Prehospital care; Students; Intubation protocols.

\section{CONOCIMIENTO EN ACCESO A LA VÍA PERIFÉRICA DEFINITIVA Y VASCULAR DE ESTUDIANTES DE ATENCIÓN PREHOSPITALARIA}

Resumen - Se evaluó el conocimiento del acceso a la vía aérea definitiva y vascular periférica de los tecnólogos en atención prehospitalaria en formación, a través de un cuestionario de conocimiento. La muestra se aplicó a los 84 estudiantes matriculados y activos en el programa de Tecnología de Atención Prehospitalaria de la Corporación Universitaria Rafael Nuñez en el segundo período de 2018 del segundo al sexto semestre. Al evaluar a los estudiantes, se descubrió que tienen poco poder de los conocimientos básicos para realizar procedimientos invasivos en la vía vascular periférica, destacando la falta de protocolos, manejo y función de soluciones cristaloides, equipos de venoclisis y catéteres de acuerdo con su enumeración que se utilizan. También hubo una falta de conocimiento en los protocolos para el manejo de la vía aérea, el manejo adecuado del equipo de intubación endotraqueal, las indicaciones y contraindicaciones para la intubación endotraqueal definitiva y los beneficios que genera en los pacientes.

Palabras Clave: Vía vascular periférica; Atención prehospitalaria; Estudiantes; Protocolos de intubación. 


\title{
Introduction
}

Prehospital care is understood as the help given to people where their life is in danger and / or affecting their mental and physical integrity; It is provided in order to achieve the limitation of functional organic damage from the first contact until arrival and delivery to a facility for medical care (Bossers et al., 2015). There are several alternative methods for the management of the patient's airway in which the final one is endotracheal intubation. The decision to use an alternative device should be made after the assessment of the airway taking into account the possible benefits and risks to establish a plan that seeks the best interest of the patient in a given situation (Suleimenov et al., 2017; Al-Thani et al., 2014; Zhang et al., 2013; Kothari et al., 1999). On the other hand, in the circulation the knowledge and skill of good vascular access is necessary for the stabilization of the patient. Obtaining a peripheral vascular access has two fundamental purposes: therapeutic and diagnostic. In the prehospital setting, its use is aimed at therapeutic purposes, among which the main ones are the administration of fluids to restore blood volume. Following correctly the main care protocols in the aforementioned procedures to the patient who requires it, would increase the likelihood that care will be effective (Posada et al., 2019; Balikuddembe et al., 2017; Marrugo, 2017).

The Prehospital Care Technologist is a person able to act effectively during the initial stabilization of the patient. The knowledge, skills and dexterity allow you to approach, prevent and reduce mortality in the patient caused by diseases or traumas. Among the knowledge that the Technologist in Prehospital Care must have is access to the airway and vascular access of the human body (Sahoo et al., 2018; Chaitach et al., 2014; Tuma et al., 2014). The airway allows to incorporate oxygen to the body, which is transported to the lungs that contain inside the pulmonary alveoli, where it is then taken to the blood and in conjunction with the Circulatory System is distributed through all other structures vital. The insufficient supply of oxygenated blood to the brain; Hypoxemia is one of the causes of death in traumatized patients (Hassan et al., 2019; Cotogni \& Pittiruti, 2014). The prevention of this requires a permeable and safe airway with adequate ventilation. To carry out this requires knowledge and technique implementing simple and complex devices (intubation) with some protocols that allow procedures to be performed (Ebrahimian et al., 2014; Villalba \& Vargas, 2017). At the time of fluid replacement, the channeling of a peripheral vein is used, this is a technique that allows have a permeable pathway of the patient's vascular system, through this is administered serotherapy, medication and nutrition (Oludara et al., 2014; Casares, 2004; Salleras \& Fuentes, 2016; Gutiérrez \& Vilches, 2017).

An erroneous procedure could cause an additional risk to the patient and diminish the possibility of success in his attention. For this reason, the aim of the present study is to evaluate the knowledge of access to the definitive airway and peripheral vascular pathway that the Technologists in Prehospital Care in training of the CURN have during the second period of 2018, taking into account that currently T-APH we are immersed in different scenarios where it is necessary to apply the main knowledge in the management of the airway and vascular. The participating students would be those who have passed the subjects: Introduction to Prehospital Care, Basic Health Care Training in APH, Prehospital Care I, Prehospital Care II and Prehospital Care III.

\section{Material and Methods}

\author{
IPSA SCIENTIA - Vol. 3 N$^{\circ} 1-2018$
}


The following work is considered within cross-section descriptive studies. The students of the program Technology in Prehospital Care of the Rafael Núñez University Corporation. The sample will apply to the 84 students enrolled and active in the Pre-Hospital Care Technology program of the CURN in the second period of 2018 from the second to the sixth semester (Table 1).

\begin{tabular}{|c|c|c|c|c|c|c|}
\hline Semester & 2nd & 3rd & 4th & 5th & 6th & Total \\
\hline No. of Students & 16 & 23 & 23 & 13 & 9 & 84 \\
\hline
\end{tabular}

Table 1. Sample of students from the Prehospital Care Technology program (CURN).

Inclusion Criteria: Students of Technology in Pre-hospital Care of the CURN who have studied and approved the following subjects: a) Introduction to Prehospital Care; b) Basic Care Training in Prehospital ; c) Care; d) APH I; e) APH II; f) APH III.

Exclusion criteria: CURN T-APH students who have not completed and passed the subjects that are NOT related to a definitive airway: introduction in prehospital care and basic healthcare training in peripheral vascular prehospital care: introduction in prehospital care.

Ethical considerations: This research was based on the principles of ethics, it was taken into account the prior consent of the same to participate, taking into account all aspects established in this regard there is no academic or commercial conflict in the search to improve the quality of the aspects studied the Technology Program in Prehospital Care.

\section{Results and Discussion}

The results obtained from the application of the instrument to the students of Technology in Prehospital Care in the second period of 2018 are presented below. See graphs 1 to 29 and Tables 1 to 30.

\section{QUESTIONNAIRE}

VASCULAR ACCESS: Students of 2-6 semester. Total: 84

1. Obtaining vascular access is a quick and easy procedure that has a time: 77 answers

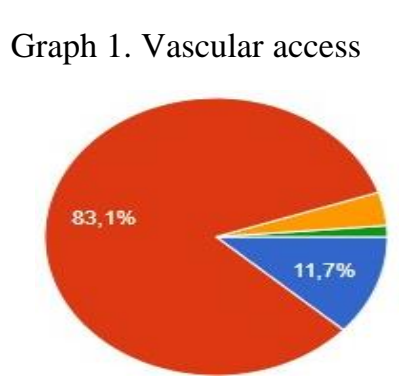

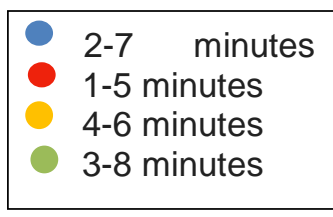

Nomenclature

Table 2. Basic

Source: Author

Guidelines for Prehospital Medical Care,

Page 158.

\begin{tabular}{|l|l|l|}
\hline Correct answer & Wrong answer & They did not respond \\
\hline 64 Students $(83.1 \%)$ & 13 Students $(16.9 \%)$ & 7 Students \\
\hline
\end{tabular}

IPSA SCIENTIA - Vol. $3 \mathrm{~N}^{\circ} 1-2018$ 
Source: Author

2. In the peripheral catheterization of upper limbs the first thing that should be valued:83 answers.

Graph 2. Peripheral catheterization of upper limbs

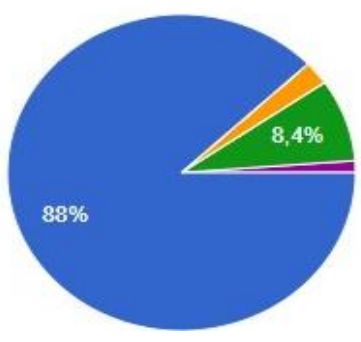

Source: Author
The back of the hand and continue on the forearm and elbow flexure.

Hand flexion, arterial elasticity and capillary refill.

Signs of phlebitis, pain and continuous forearm

Capillary refill, signs of phlebitis and pain.

Flexure of the knee and arterial elasticity.

Nomenclature

Table 3. Basic Guidelines for Prehospital Medical Care Page 160.

\begin{tabular}{|l|l|l|}
\hline Correct answer & Wrong answer & They did not respond \\
\hline 73 Students $(88 \%)$ & 10 Students $(12 \%)$ & 1 Student \\
\hline
\end{tabular}

Source: Author

3. According to the protocol for peripheral vascular access, one of the first steps are: 82 anwers.

Graph 3. Peripheral vascular access

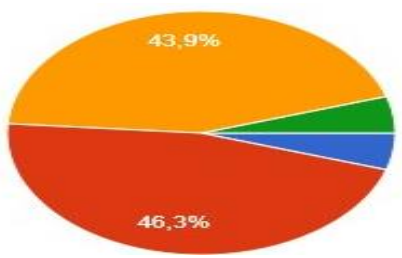

Source: Author
Prepare the equipment, feel the vein, wash the hands.

Put on gloves, prepare the equipment, inform the patient about the procedure.

Explain the procedure to the patient, wash hands, put on gloves.

Feel the vein, clean the area and channel.

Nomenclature

Table 4. Basic Guidelines for Prehospital Medical Care Page 161.

\begin{tabular}{|c|l|c|}
\hline Correct answer & Wrong answer & They did not respond \\
\hline 36 Students (43.9\%) & 46 Students (56.1\%) & 2 Students \\
\hline
\end{tabular}

Source: Author

IPSA SCIENTIA - Vol. 3 N$^{\circ} 1-2018$ 
4. Every few hours the venoclysis equipment is changed. 82 answers.

Graph 4. Venoclysis equipment

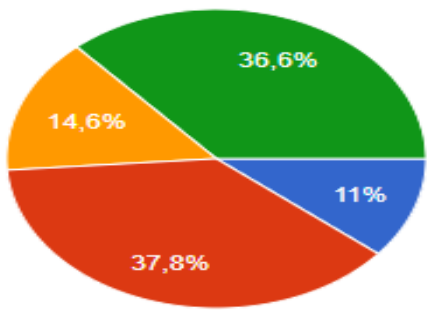

Every 35-48 hours

Every 48-72 hours

Every 20-35 hours

Every 12-24 hours

Nomenclature

Source: Author

Table 5. Basic Guidelines for Prehospital Medical Care Page 162.

\begin{tabular}{|c|c|l|}
\hline Correct answer & Wrong answer & They did not respond \\
\hline 31 Students (37.8\%) & 51 Students (62.2\%) & 2 Students \\
\hline
\end{tabular}

Source: Author

5. Among the signs and symptoms of phlebitis we can find: 82 answers.

Graph 5. Signs and symptoms of phlebitis

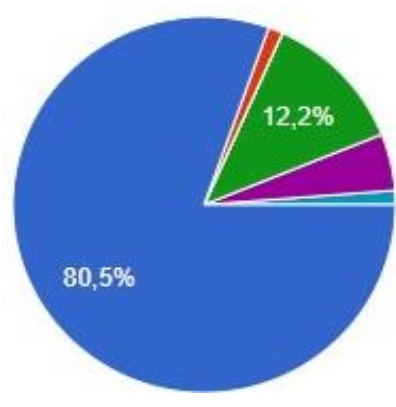

Source: Author
Moderate pain, redness in the area or venous tract.

Redness in the area or venous tract, local heat, dry skin.

Complete inflammation of the limb, redness of the area and necrosis.

Redness of the area and obstruction of the way.

Complete inflammation of the limb. Redness of the area, local cold

Nomenclature

Table 6. Basic Guidelines for Prehospital Medical Care Page 159.

\begin{tabular}{|c|l|l|}
\hline Correct answer & Wrong answer & They did not respond \\
\hline 66 Students $(80.5 \%)$ & 16 Students $(19.5 \%)$ & 2 Students \\
\hline
\end{tabular}

Source: Author

6. 2-year-old patient, in need of fluid replacement iv. ¿Which catheter number would be the one indicated?

IPSA SCIENTIA - Vol. $3 \mathrm{~N}^{\circ} 1-2018$ 
82 answers.

Graph 6. Intravenous fluid replacement

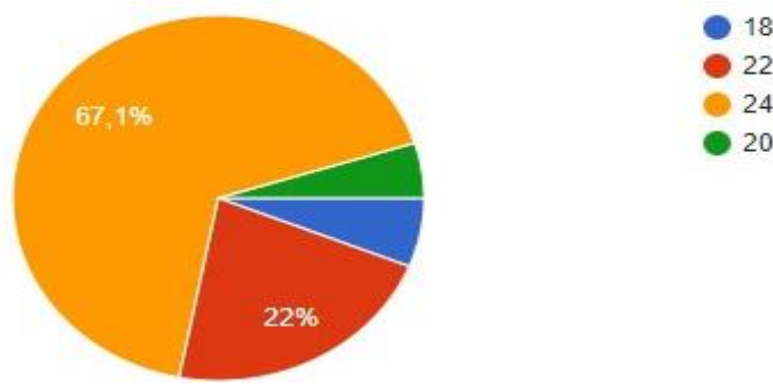

Nomenclature

Source: Author

Table 7. Basic guidelines for prehospital medical care pages 160 .

\begin{tabular}{|c|l|l|}
\hline Correct answer & Wrong answer & They did not respond \\
\hline 55 Students $(67.1 \%)$ & 27 Students $(32.9 \%)$ & 2 Students \\
\hline
\end{tabular}

Source: Author

7. The best crystalloid solution for the treatment of hemorrhagic shock is: 82 answers.

Graph 7. Treatment of hemorrhagic shock

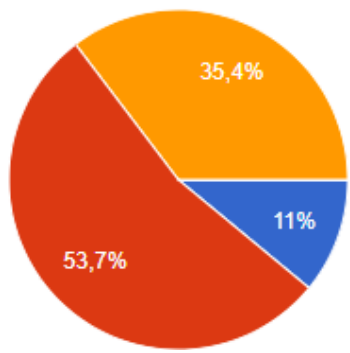

Dextrose

Ringer lactato

Saline solution

$0.5 \%$ saline solution

Nomenclature

Source: Author

Table 8. Basic guidelines for prehospital medical care pages 160 .

\begin{tabular}{|c|l|l|}
\hline Correct answer & Wrong answer & They did not respond \\
\hline 44 Students (53.7\%) & 38 Students (46.3\%) & 2 Students \\
\hline
\end{tabular}

Source: Author

8. What are the main therapeutic purposes of peripheral vascular access? 82 answers

Graph 8. Therapeutic purposes of peripheral vascular access

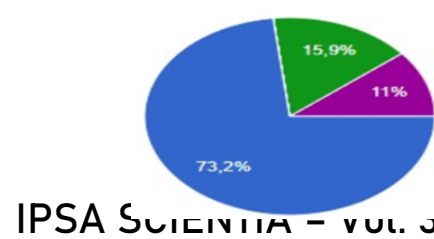

Source: Author
Administer medication, replacement of erythrocytes.

Administer saline solution, blood plasma replacement.

Percutaneous puncture and administer

Administer medication, replacement of erythrocytes. 
Table 9. Basic guidelines for prehospital medical care pages 159.

\begin{tabular}{|l|l|l|}
\hline Correct answer & Wrong answer & They did not respond \\
\hline 60 Students $(73.2 \%)$ & 22 Students $(26.9 \%)$ & 2 Students \\
\hline
\end{tabular}

Source: Author

9. The drip factor of the normo-dropper venoclysis equipment is: 82 answers

Graph 9. Drip factor
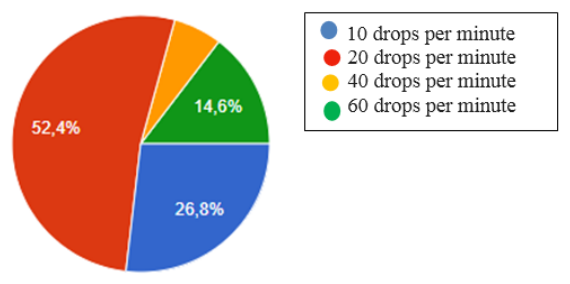

Nomenclature

Source: Author

Table 10. Basic guidelines for prehospital medical care pages 159.

\begin{tabular}{|l|l|l|}
\hline Correct answer & Wrong answer & They did not respond \\
\hline 43 Students $(52.4 \%)$ & 39 Students $(47.6 \%)$ & 2 Students \\
\hline
\end{tabular}

Source: Author

10. The main contraindications for vascular access are: 82 answers

Graph 10. Contraindications for vascular access

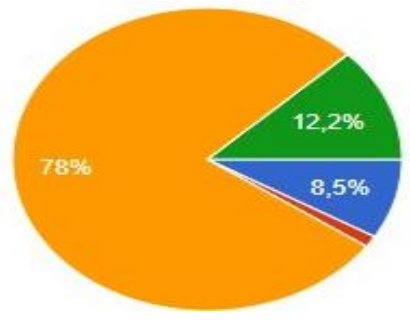

Source: Author

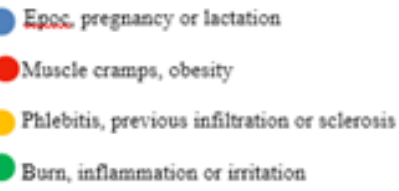

Epcs, pregnancy or lactation

Muscle cramps, obesity

Plebitis, previous infileration or selerosis

Burn, inflammation or imitation

Nomenclature

Table 11. Basic pre-hospital medical care guides pages 159 .

IPSA SCIENTIA - Vol. $3 \mathrm{~N}^{0} 1-2018$ 
Knowledge in access to the definitive and vascular peripheral aerial of prehospital care

\begin{tabular}{|c|l|l|}
\hline Correct answer & Wrong answer & They did not respond \\
\hline 64 Students (78\%) & 18 Students (22\%) & 2 Students \\
\hline
\end{tabular}

Source: Author

ACCESS TO THE AIRLINE: Students from 4-6 semester. Total: 45

1. Endotracheal intubation is indicated in patients: 45 answers

Graph 11. Endotracheal intubation

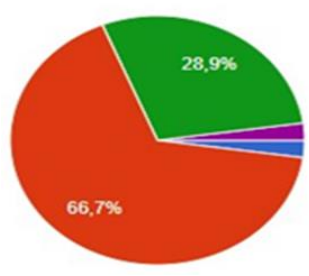

Source: Author

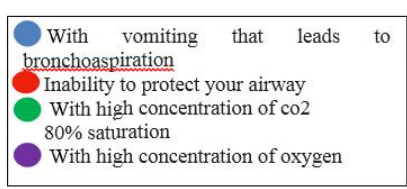

Nomenclature

Table 12. PHTLS Page 181

\begin{tabular}{|l|l|l|}
\hline Correct answer & Wrong answer & They did not respond \\
\hline 30 Students $(66.7 \%)$ & 15 Students $(33.3 \%)$ & 0 Students \\
\hline
\end{tabular}

Source: Author

2. Primary mnemonic to evaluate the difficulty in endotracheal intubation: 45 answers

Graph 12. Primary mnemonic

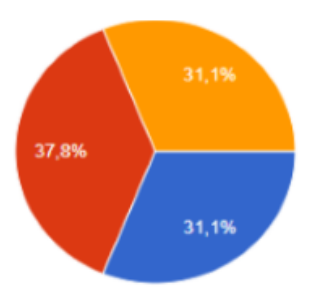

Source: Author

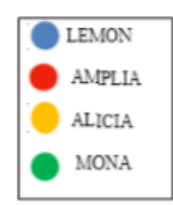

Nomenclature

Table 13. PHTLS Page 180

\begin{tabular}{|l|l|l|}
\hline Correct answer & Wrong answer & They did not respond \\
\hline 14 Students $(31.1 \%)$ & 31 Students $(68.9 \%)$ & 0 Students \\
\hline
\end{tabular}

Source: Author

3. Endotracheal intubation is contraindicated in patients: 45 answers

Graph 13. Endotracheal intubation

IPSA SCIENTIA - Vol. 3 N$^{\circ} 1-2018$ 


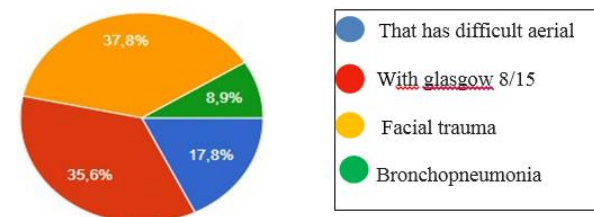

Source: Author

Nomenclature

Table 14. PHTLS Page 181

\begin{tabular}{|l|l|l|}
\hline Correct answer & Wrong answer & They did not respond \\
\hline 14 Students (37.8\%) & 28 Students $(62.2 \%)$ & 0 Students \\
\hline
\end{tabular}

Source: Author

4. Prolonged attempts at failed intubation create complications in patients as: 45 answers.

Graph. 14. Failed intubation
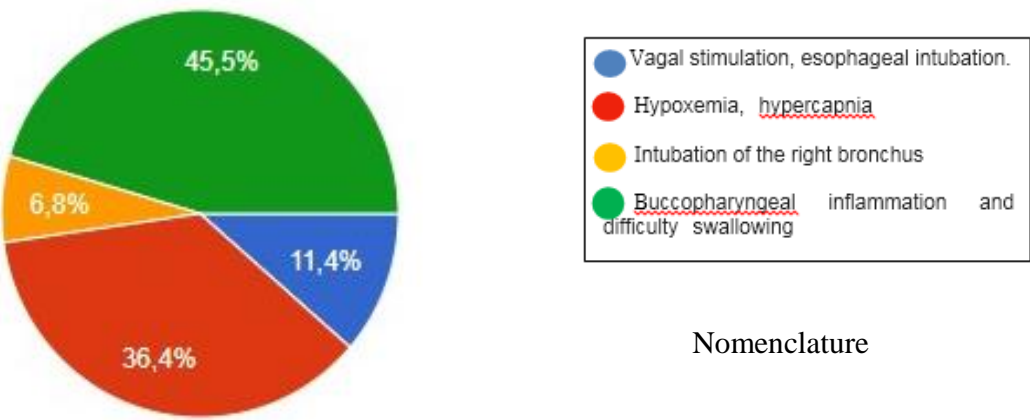

Source: Author

Nomenclature

Table 15. PHTLS Page 184

\begin{tabular}{|l|l|l|}
\hline Correct answer & Wrong answer & They did not respond \\
\hline 16 Students $(36.4 \%)$ & 29 Students $(63.6 \%)$ & 1 Student \\
\hline
\end{tabular}

Source: Author

5. In a patient with a perfusion rhythm, monitoring serves as the gold standard to determine the location of the endotracheal tube. 45 answers.

Graph 15. Monitoring to determine the location of the endotracheal tube.

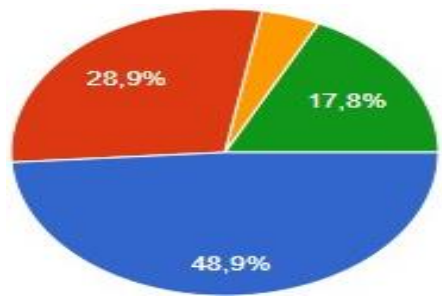

Electrocardiogram

$\mathrm{CO} 2$

Vital signs

Oxygen saturation

Nomenclature

IPSA SCIENTIA - Vol. 3 N$^{\circ} 1-2018$ 
Source: Author Table 16. PHTLS Page 185

\begin{tabular}{|l|l|l|}
\hline Correct answer & Wrong answer & They did not respond \\
\hline 13 Students $(28.9 \%)$ & 32 Students $(71.1 \%)$ & 0 Students \\
\hline
\end{tabular}

Source: Author

6. According to the PHTLS, the factors that contribute to a difficult intubation are: 45 answers Graph 16. Difficult intubation

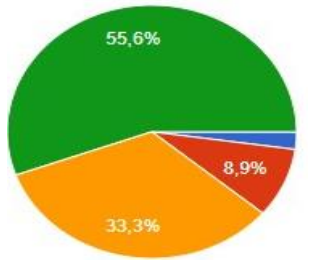

Source: Author
Macrodontia, anodontics

Obesity, skull fracture

Facial trauma, bleeding inside the airway

Cervical trauma and unstable chest

Nomenclature

Table 17. PHTLS Page 179

\begin{tabular}{|c|l|l|}
\hline Correct answer & Wrong answer & They did not respond \\
\hline 15 Students $(33.3 \%)$ & 30 Students $(66.7 \%)$ & 0 Students \\
\hline
\end{tabular}

Source: Author

7. Among the clinical evaluations to verify the placement of the endotracheal tube are: 45 answers.

Graph 18. Endotracheal tube placement

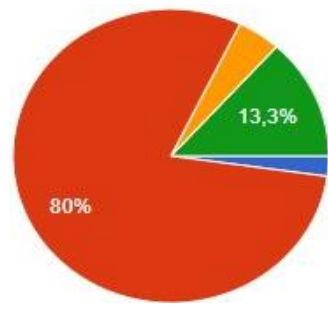

Source: Author
Pulse oximeter

Presence of bilateral sounds, absence of ounds above the epigastrium

Regular rhythm of breathing, normal TA

Monitoring of vital signs, absence of bilateral sounds

$$
\text { Nomenclature }
$$

Table 19. PHTLS Page 185

\begin{tabular}{|l|l|l|}
\hline Correct answer & Wrong answer & They did not respond \\
\hline 36 Students $(80 \%)$ & 9 Students $(20 \%)$ & 0 Students \\
\hline
\end{tabular}

Source: Author

8. What would be the complication of excessive filling of the balloon of the endotracheal tube. 45 answers

Graph 19. Overfilling of the endotracheal tube balloon

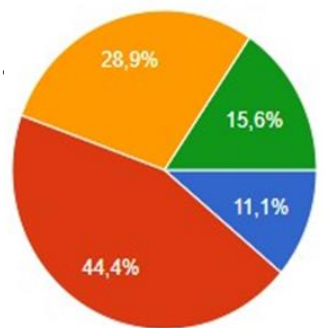

Source: Author
Pulmonary edema

Alveolar hypercapnea

Tracheal ischemia

Emphysema in lung parenchyma 
Table 20. Basic Guidelines for Prehospital Medical Care Page 90

\begin{tabular}{|l|l|l|}
\hline Correct answer & Wrong answer & They did not respond \\
\hline 13 Students $(44.4 \%)$ & 32 Students $(55.6 \%)$ & 0 Students \\
\hline
\end{tabular}

Source: Author

9. Endotracheal intubation is the preferred method to control and secure the airway since it allows 44 answers

Graph 20. Endotracheal intubation. Preferred method of controlling and securing the airway.

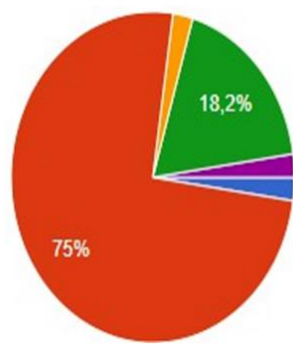

Source: Author

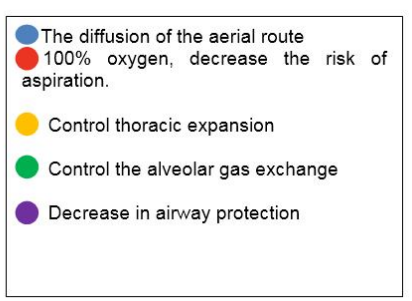

Nomenclature

Table 21. PHTLS Page 180

\begin{tabular}{|l|l|l|}
\hline Correct answer & Wrong answer & They did not respond \\
\hline 33 Students $(75 \%)$ & 12 Students $(25 \%)$ & 1 Student \\
\hline \multicolumn{2}{|c|}{ Source: Author } \\
\hline
\end{tabular}

Source: Author

10. It is not part of the standard components of an intubation device: 45 answers

Graph 21. Standard components of an intubation device.

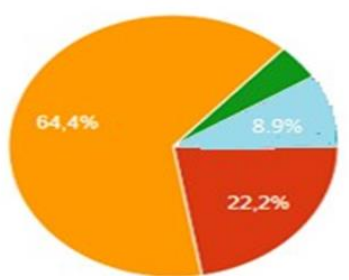

Source: Author
Magill pincers

Automatic external defibrillator

$10 \mathrm{cc}$ siringes

Capnography system with visual wave

Nomenclature

IPSA SCIENTIA - Vol. 3 NN$^{\circ} 1-2018$ 
Table 22. PHTLS Page 144

\begin{tabular}{|c|l|l|}
\hline Correct answer & Wrong answer & They did not respond \\
\hline 29 Students $(64.4 \%)$ & 16 Students $(35.6 \%)$ & 0 Students \\
\hline
\end{tabular}

Source: Author

ADDITIONAL QUESTIONS: Students of 4-6 semester. Total: 45

1. Do you believe that the hours of practice in airway access provided by the program during the semester are enough for your training as a technologist in APH. 45 answers.

Graph. 22. Hours of practice

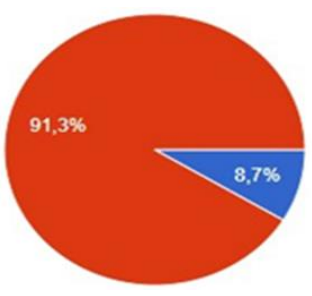

Source: Author

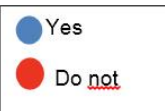

Nomenclature

Table 23. Hours of practice

\begin{tabular}{|c|c|}
\hline YES & DO NOT \\
\hline 3 Students $(8,7 \%)$ & 42 Students $(91,3 \%)$ \\
\hline
\end{tabular}

Source: Author

2. If your answer was No, how many hours per week do you think are necessary?: 45 answers.

Graph 23. Hours needed for practice

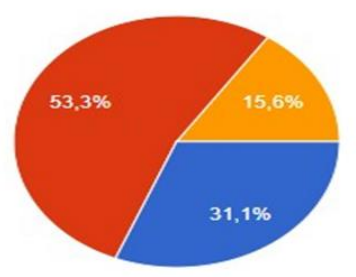

Source: Author

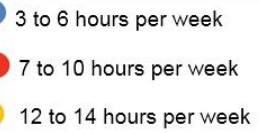

3 to 6 hours per week

7 to 10 hours per week

12 to 14 hours per week

Nomenclature

IPSA SCIENTIA - Vol. $3 \mathrm{~N}^{\circ} 1-2018$ 
Table 24. Hours needed for practice

\begin{tabular}{|l|l|l|}
\hline 3 a 6 hours per week & $\mathbf{7}$ a 10 hours per week & 12 a 14 hours per week \\
\hline 14 Students $(31,1 \%)$ & 24 Students $(53,3 \%)$ & 7 Students $(15,6 \%)$ \\
\hline
\end{tabular}

Source: Author

3. During your semester, how many hours of intubation do you practice? 45 answers

Graph 24. Hours of practice intubation

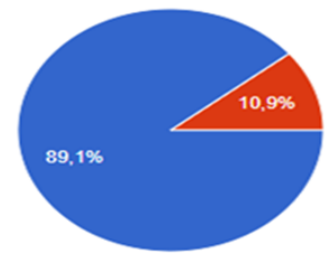

Source: Author

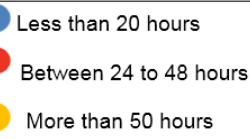

Nomenclature

Table 25. Hours of practice intubation

\begin{tabular}{|l|l|l|}
\hline Less than 20 hours & Between 24 to 48 hours & More than 50 hours \\
\hline 41 Sudents $(89,1 \%)$ & 5 Students $(10,9 \%)$ & 0 Students \\
\hline
\end{tabular}

Source: Author

4. Do you feel able to place an endotracheal tube in a patient with indications of endotracheal intubation and have your airway compromised? 45 answers.

Graph 25. Ability to place an endotracheal tube

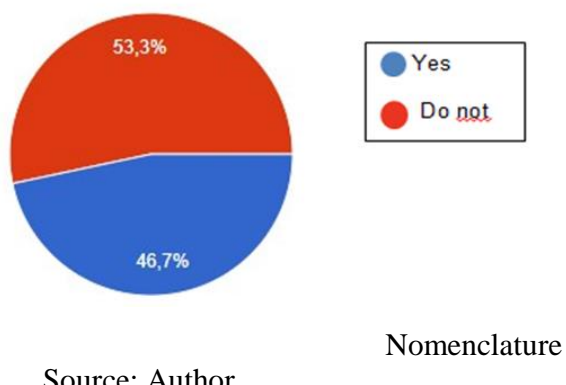

IPSA SCIENTIA - Vol. 3 N$^{\circ} 1-2018$ 
Table 26. Ability to place an endotracheal tube

\begin{tabular}{|c|l|}
\hline YES & DO NOT \\
\hline 21 Students $(46.7 \%)$ & $\bullet$ Students $(53,3 \%)$ \\
\hline
\end{tabular}

Source: Author

5. Do you know the legal consequences that can be incurred in case of trauma to the patient in the endotracheal intubation procedure? 45 answers.

Graph 26. Legal consequences in case of trauma to the patient

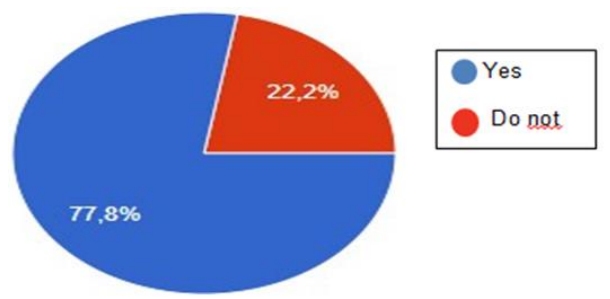

Table 27. Legal consequences in case of trauma to the patient

\begin{tabular}{|c|c|}
\hline YES & DO NOT \\
\hline 35 Students $(77.8 \%)$ & 10 Students $(22.2 \%)$ \\
\hline
\end{tabular}

Source: Author

ADDITIONAL QUESTIONS: Students from 2-6 semester.

6. Do you believe that the hours in peripheral vascular access provided by the program during the semester are enough for your training as a technologist in APH 0 Of 73 correct answers

Graph 27. Peripheral vascular access training hours

IPSA SCIENTIA - Vol. $\left.3\right|_{\text {DO NOT }} ^{\text {Dona } 8}$

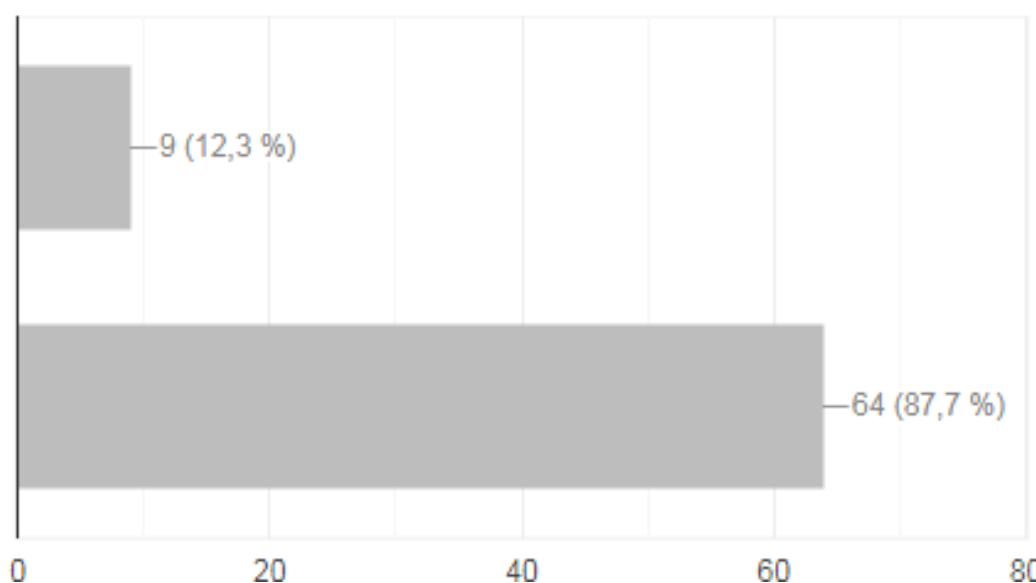


Table 28. Horas de formación en acceso vascular periférico

\begin{tabular}{|c|c|c|}
\hline Yes & \multicolumn{1}{|c|}{ Do not } & They did not respond \\
\hline 9 Students $(12,3 \%)$ & 64 Students $(87,7 \%)$ & 11 Students \\
\hline
\end{tabular}

Source: Author

7. If your answer was No, how many hours per week do you think are necessary?:73 answers

Graph 28. Sufficiency of training hours in peripheral vascular access
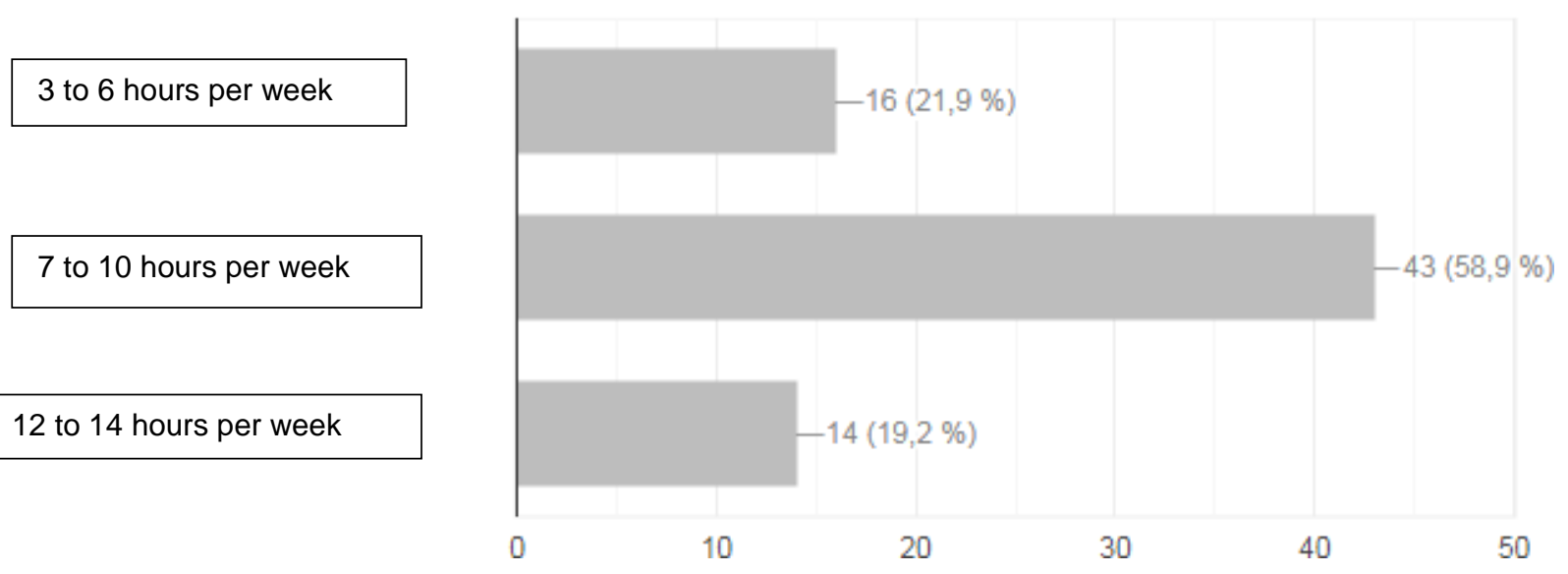

Source: Author

Table 29. Sufficiency of training hours in peripheral vascular access

\begin{tabular}{|c|c|c|c|}
\hline 3 to 6 hours per week & $\begin{array}{l}7 \text { to } 10 \text { hours per } \\
\text { week }\end{array}$ & $\begin{array}{l}12 \text { to } 14 \text { hours per } \\
\text { week }\end{array}$ & $\begin{array}{l}\text { They did not } \\
\text { respond }\end{array}$ \\
\hline 16 Students $(21,9 \%)$ & 43 Students $(58,9 \%)$ & 14 Students $(19,2 \%)$ & 11 Students \\
\hline
\end{tabular}

Source: Author

8. During your semester, how many hours of practical channeling? 73 answers.

Graph 29. Hours of hands-on channeling

Less than 20 hours

Between 24 to 48

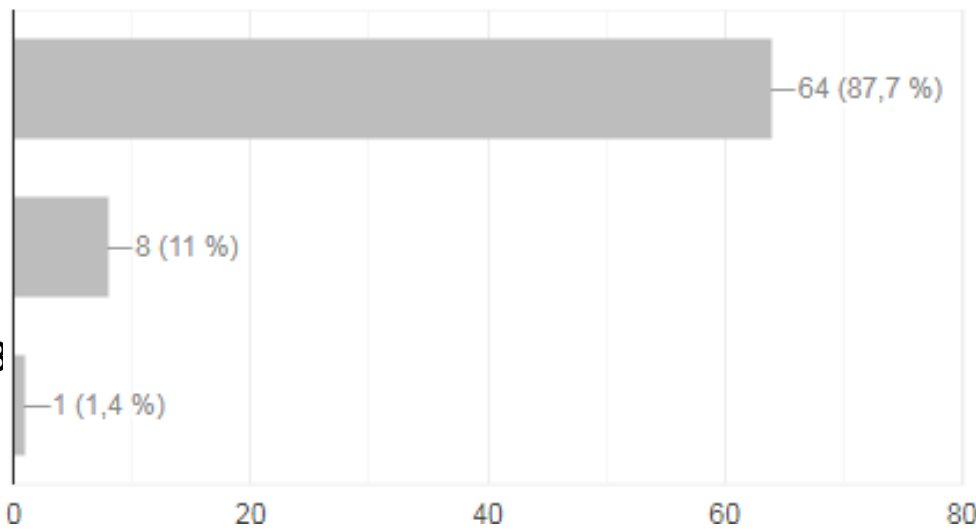


More than 50 hours

Source: Author

Table 30. Hours of hands-on channeling

\begin{tabular}{|l|l|l|l|}
\hline $\begin{array}{l}\text { Less than 20 } \\
\text { hours }\end{array}$ & $\begin{array}{l}\text { Between 24 to 48 } \\
\text { hours }\end{array}$ & $\begin{array}{l}\text { More than 50 } \\
\text { hours }\end{array}$ & They did not respond \\
\hline $\begin{array}{l}\text { 64 Sudents } \\
(87,7 \%)\end{array}$ & 8 Students $(11 \%)$ & 1 Students $(1.4 \%)$ & 11 Students \\
\hline
\end{tabular}

Source: Author

\section{Conclusions}

When evaluating the students we found that they have little empowerment of the basic knowledge to perform invasive procedures in the peripheral vascular pathway, highlighting the lack of protocols, management and function of crystalloid solutions, venoclisis equipment and catheters according to their enumeration which are used. There was also a lack of knowledge in protocols for airway management, adequate management of endotracheal intubation equipment, indications and contraindications for definitive endotracheal intubation and the benefits it generates in patients. The students highlight in the answers of each of the additional questions that the hours offered during the semesters for the invasive procedures are not enough for the training as Technologists in Prehospital Care, it is deduced that this is part of the reason for the deficiency in the knowledge that are evident in the results obtained.

\section{References}

- Al-Thani, H., El-Menyar, A., \& Latifi, R. (2014). Prehospital versus Emergency Room Intubation of Trauma Patients in Qatar: A-2-year Observational Study. North American journal of medical sciences, 6(1), 12-18.

- Balikuddembe, J. K., Ardalan, A., Khorasani-Zavareh, D., Nejati, A., \& Raza, O. (2017). Weaknesses and capacities affecting the Prehospital emergency care for victims of road traffic incidents in the greater Kampala metropolitan area: a cross-sectional study. BMC emergency medicine, 17(1), 29.

- Bossers, S. M., Schwarte, L. A., Loer, S. A., Twisk, J. W., Boer, C., \& Schober, P. (2015). Experience in Prehospital Endotracheal Intubation Significantly Influences Mortality of Patients with Severe Traumatic Brain Injury: A Systematic Review and Meta-Analysis. PloS one, 10(10), e0141034.

- Casares, N. G. (2004). Vía venosa difícil: estrategias. emergencias, 16, 201-204.

IPSA SCIENTIA - Vol. $3 \mathrm{~N}^{\circ} 1-2018$ 
- Chaitach Jansamood, Akkapon Poomee and Phadungsak Khomyos, 2014. Condition on Infectious Waste Management of Tambon Health Promoting Hospital in Don Chan District Kalasin Province. Research Journal of Applied Sciences, 9: 975978.

- Cotogni, P., \& Pittiruti, M. (2014). Focus on peripherally inserted central catheters in critically ill patients. World journal of critical care medicine, 3(4), 80-94.

- Ebrahimian, A., Seyedin, H., Jamshidi-Orak, R., \& Masoumi, G. (2014). Exploring Factors Affecting Emergency Medical Services Staffs' Decision about Transporting Medical Patients to Medical Facilities. Emergency medicine international, $2014,215329$.

- Gutiérrez, E., Carranza, M. L., \& Vilches, P. L. J. (2017). Catéteres venosos de inserción periférica (PICC): un avance en las terapias intravenosas de larga permanencia. Nutr Clín Med, 11(2), 114-127.

- Kothari, R. U., Pancioli, A., Liu, T., Brott, T., \& Broderick, J. (1999). Cincinnati prehospital stroke scale: reproducibility and validity. Annals of emergency medicine, 33(4), 373-378.

- Marrugo Ligardo, Y. (2017). Health and safety management system in latin america: a review from the hseq integration. IPSA SCIENTIA. Revista Científica Multidisciplinaria, 2(1), 38-45.

- Oludara M, Idowu O, Ibrahim N, Mustafa I, Ajani A, Balogun R, Solagberu B. Emergency Medical Services Outcome Assessment in Lagos, Nigeria: Review of Cases of 'Brought in Dead'' Patients. Open Access Maced J Med Sci. 2014 ;2(2):253-6.

- Salleras-Duran, L., \& Fuentes-Pumarola, C. (2016). Cateterización periférica ecoguiada frente a la técnica tradicional. Enfermería Clínica, 26(5), 298-306.

- Suleimenov, B., Laura Sugurova, Aituar Suleimenov and Alibek Suleimenov, 2017. Neuro Fuzzy Model For Equipment Health Management in Yellow Phosphorus Production Process. Journal of Engineering and Applied Sciences, 12: 78897896.

- Tuma, M., El-Menyar, A., Abdelrahman, H., Al-Thani, H., Zarour, A., Parchani, A., ... Latifi, R. (2014). Prehospital intubation in patients with isolated severe traumatic brain injury: a 4-year observational study. Critical care research and practice, 2014, 135986.

- Villaba Vimos, V., \& Vargas Ortiz, L. (2017). Work absenteeism in workers of an agrochemical manufacturing plant. IPSA SCIENTIA. Revista Científica Multidisciplinaria, 2(1), 10-20.

- Zhang, L., Keogh, S., \& Rickard, C. M. (2013). Reducing the risk of infection associated with vascular access devices through nanotechnology: a perspective. International journal of nanomedicine, 8, 4453-4466.

IPSA SCIENTIA - Vol. 3 NN$^{\circ} 1-2018$ 